\title{
A ESCOLHA PELO SOFRIMENTO
}

\author{
Felipe de Oliveira Ferreira Santos ${ }^{1}$; Malcom Guimarães Rodrigues ${ }^{2}$. \\ 1. Bolsista FAPESB/CNPq, Graduando em Psicologia, Universidade Estadual de Feira de Santana, e-mail: \\ felipedeoliveirafsantos@gmail.com \\ 2. Orientador, Departamento de Ciências Humans e Filosofia, Universidade Estadual de Feira de Santana, e-mail: \\ malcomgr@gmail.com
}

PALAVRAS-CHAVE: Sartre; esolha; sofrimento.

\section{INTRODUÇÃO}

Nosso ponto de partida foi o questionamento: de que maneira o existencialismo sartriano, a partir do conceito de escolha original, pode explicar a escolha pela infelicidade como modo de vida? Sartre dirá em $O$ ser e o nada (1943) que poucas vezes o projeto que demarca uma vida é realizado com alegria. A vida é repleta de tristezas, o sofrimento e a melancolia, não raro, são a maneira pela qual escolhemos habitar o chamado "nosso mundo". O objetivo geral, portanto, foi percorrer e confrontar o conceito sartriano de escolha original frente ao dilema ético da escolha pelo sofrimento. Através de sua ontologia fenomenológica, o autor analisa profundamente os modos pelos quais a escolha original pode ser feita na má-fé. Aqui, foi necessário interrogar o conceito de má-fé que, segundo o autor, pode ser indicado em certas condutas como a "automentira", que está longe de ser uma simples mentira interpessoal. A partir daí, foi preciso reconhecer: a liberdade de escolha localiza-se em toda parte, e a escolha original "um verdadeiro irredutível (...) uma exigência fundamentada em uma compreensão pré-ontologica da realidade humana" (1943, p. 686). A dificuldade do conceito de escolha original reside, principalmente, em sua grandeza. Evidenciada nas atitudes mais banais, na unidade de um só ato. O estudo do comportamento humano conduzirá Sartre ao desenvolvimento de uma psicanálise aos moldes "existenciais": um método, antes de tudo, hermenêutico. "É sobretudo por uma comparação entre as diversas tendências empíricas de um sujeito que iremos tentar descobrir e destacar o projeto fundamental comum a todas (...) em cada uma delas acha-se a pessoa na sua inteireza" (2014, p. 690). À guisa de uma leitura rigorosa de sua proposta de psicanálise, a viabilidade e relevância desse projeto residiram na possibilidade constatada de uma modificação radical de nossa escolha original, pois a escolha não é um impulso inicial cujo percurso me caberá realizar: a escolha é nadificação e, logo, sua reassunção contínua é necessária. O rompimento será o momento em que a angústia é testemunha de nossa condição injustificável, em que já nos vemos comprometidos num futuro de maneira distinta. E também por acreditar que a dor precisa ser transformada, nunca contrariada ou suprimida - como faz supor a leitura das predominantes correntes biologicistas.

\section{MATERIAL E MÉTODOS}

Os materiais utilizados foram prioritariamente de ordem textual: livros, artigos, textos etc. A metodologia consistiu, basicamente, em: 1. Encontros com o orientador; 2. Leituras e análises de textos; 3. Fichamentos e novas discussões com o orientador; 4. Análises críticas e produção de textos e relatórios. Os encontros com o orientador e a 
participação nos grupos de estudo e pesquisa foram fundamentais, especialmente no início da pesquisa, momento no qual as primeiras leituras foram discriminadas e analisadas. Depois das primeiras leituras e fichamentos, a partir de novos encontros com o orientador, passamos à produção do primeiro relatório. Com o avanço da pesquisa, fez parte da metodologia a produção de textos para eventual publicação e a participação em eventos para apresentação e discussão dos resultados parciais e/ou finais da pesquisa. Além disso, para a obtenção de uma leitura proveitosa e satisfatória, utilizamos orientação de Marconi e Lakatos (2006), os quais recomendam a adoção dos seguintes aspectos fundamentais: atenção - no sentido de buscar entendimento, assimilação e apreensão dos conteúdos do texto, intenção, reflexão, espírito crítico - de modo a não admitir ideias sem análise ou ponderação, análise e síntese, ou seja, reconstituir as partes analisadas, elaborando um resumo dos aspectos essenciais.

\section{RESULTADOS E/OU DISCUSSÃO}

Nossa investigação esclareceu que a existência precede a essência, pois o mecanismo de funcionamento da consciência (o absoluto de subjetividade), é a nadificação perpétua das coisas. Dessa forma, a escolha pelo sofrimento não pode ser uma prisão perpétua, por mais difícil que possa ser a morte de um ente querido ou as dívidas acumuladas. É preciso que se estabeleça a escolha original constantemente, em cada ato. Se reestabeleço uma conduta triste, há que se dizer: faço isso em estado de liberdade.

O projeto original não se trata de um pontapé inicial, que abrirá caminhos para serem trilhados pelo homem. O projeto original, por ser nadificação, precisa ser reassumido a todo momento. Entretanto, como o projeto original é alcançado por uma comparação das diversas condutas, um conjunto do que me faço ser, para cessar a tristeza, não resolve uma mudança repentina que se repete de vez em quando. Há que se operar uma mudança contínua, anexada ao conjunto das minhas significações.

Com isso, concluímos que qualquer comportamento reassumido só faz sentido perante o cenário não alcançado norteador que a escolha original projetou. Dessa forma, mesmo se o sujeito se mantém triste por prolongado período, isso só é alcançado pela renovação da escolha. Vale lembrar, por outro lado, que essa reassunção acontece sempre em situação: quando o homem já está implicado irrefletidamente por certa facticidade. Logo, mesmo que reflita sobre a tristeza, dificilmente o sujeito irá colocá-la como um passado superado. Muitas vezes, a tristeza será reafirmada por essa reflexão impura, e é aí que reside a complexidade da questão (SARTRE, 2014).

Em verdade, na unidade de um só ato, ao homem que resolve transformar seu projeto original de tristeza, é preciso concomitantemente, tornar passado a escolha pelo sofrimento e lançar a nova escolha. Nesta concomitância, haverá início e término ao mesmo tempo, de modo que um novo projeto irromperá no preciso momento que o velho projeto se esvair. Portanto, é quando há essa abertura de nossa unidade temporal que alcançamos a transformação da rúbrica categorial (SARTRE, 2014).

Essa abertura jamais será alcançada pelo conhecimento. Há grande disparidade entre ter conhecimento e ser consciente. Não passa de presunção acreditar que a razão tenha tamanho alcance. Nossa intrínseca paixão inútil será sentida apenas enquanto angústia. Angustiados, irrefletidamente assumimos a responsabilidade por nosso projeto original. Longe de ser uma deliberação, é nesse momento que o sujeito se afasta de si próprio e vê ruir todo sofrimento que "era", e se vê imbricado responsavelmente num futuro diferente. Assim, é preciso frisar, apesar de não ser passível de conhecimento, esse instante de metamorfose será sempre constatado. São nossas escolhas que criam o cenário no qual ele nos envolve (SARTRE, 2014). 


\section{CONSIDERAÇÕES FINAIS}

Livre, o homem pode dar valor e significado a um mundo que em-si não se apresenta. Pela ação espontânea, podemos relacionar liberdade a transcendência e sempre estabelecer uma ruptura no mundo. Assim, construímos alternativas à problemática dessa pesquisa. Condenado a ser livre, é possível afastar-se da escolha pelo sofrimento.

Como observamos, Sartre foi um investigador da psicologia e elaborou uma metodologia peculiar para a análise da realidade humana. Por acreditarmos que a dor precisa ser transformada, nunca contrariada ou suprimida - como faz supor a leitura das predominantes correntes biologicistas, essa pesquisa nos instiga para um novo estudo. É preciso maior desenvolvimento nos estudos de sua Psicanálise Existencial.

Sabe-se que a sistematização prática dessa nova teoria encontra-se em algumas biografias que o próprio filósofo escreveu. Através de um posicionamento engajado, Sartre acreditava que o intelectual deveria batalhar pela construção de um mundo mais justo. A partir disso, implicou-se em interrogar os alicerces da racionalidade ocidental, o qual, queiramos ou não, é conivente com a manutenção do sistema de privilégios. É preciso superar o eruditismo e promover mudanças sociais práticas. Preterificar o sofrimento é da ordem do urgente. Além disso, pelo caráter psicológico, precisaremos também retomar alguns de seus primeiros escritos, como A Transcendência do Ego e o Esboço de uma Teoria das Emoções, em busca de pistas que dialoguem com nossas inquietações.

Assim, a presente pesquisa conduziu-nos a um novo objeto de investigação: como a Psicanálise Existencial pode contribuir, sobretudo sob um panorâma prático, à problemática existencial do homem hodierno? Há, de fato, algo que transgrida a psicologia clínica tradicional?

\section{REFERÊNCIAS}

ABBAGNANO, N. Dicionário de filosofia. São Paulo: Martins Fontes, 1998.

BERKELEY, G. Tratado sobre os princípios do conhecimento humano. São Paulo: Abril Cultural,1973.

BERGSON, H. A intuição filosófica. São Paulo: Abril cultural, 1979.

CASTRO, F. Consequências morais do conceito de má-fé em Jean Paul Sartre. 242

f. Tese (Mestrado). Instituto de Filosofia e Ciências Humanas, Pontifícia Universidade Católica do Rio Grande do Sul, 2005.

COX, G. Compreender Sartre. Trad. De Helio Magri Filho. Rio de Janeiro: Vozes, 2007.

HUME, D. Investigação sobre o entendimento humano. São Paulo: Abril Cultural, 1973

HUSSERL, E. Ideas. Nova York: Collier Masmillan, s/d.

HUSSERL, E. Meditações cartesianas - Introdução à fenomenologia. Porto: Rés editora.

HUSSERL, E. A idéia de fenomenologia. Lisboa: Edições 70.

LEOPOLDO \& SILVA, F. Conhecimento e identidade histórica em Sartre. Trans/form/ação. São Paulo, 26(2), p. 43-64, 2003.

MARCONI, M.A.; LAKATOS, E.M. Metodologia do trabalho científico: procedimentos básicos, pesquisa bibliográfica, projeto e relatório, publicações e trabalhos científicos. $6^{\text {a }}$. Ed. São Paulo: Atlas, 2006.

MOURA, C. A. R. Crítica da razão na fenomenologia. São Paulo: Nova Stella, 1989.

RICOEUR, P. Da interpretação. Rio de Janeiro: Imago, 1977.

RODRIGUES, M. Consciência e má-fé no jovem Sartre: a trajetória dos conceitos. São Paulo: Edunesp, 2010. 
ROUDINESCO, E. História da psicanálise na França. Rio de Janeiro: Jorge Zahar, 1988.

SARTRE, Jean-Paul. O ser e o nada- Ensaio de ontologia fenomenológica. Trad. de Paulo Perdigão. Rio de Janeiro: Vozes, 2014.

SARTRE, J-P. Esboço de uma Teoria das Emoções. Rio de Janeiro: Jorge Zahar, 1965.

SARTRE, J-P. O imaginário. São Paulo: Ática, 1996.

SARTRE, J-P. A transcendência do ego. Lisboa: Edições Colibri, 1994.

SARTRE, J-P. O existencialismo é um humanismo. São Paulo: Abril Cultural, 1973.

SOLOMON, A. O demônio do meio-dia: uma anatomia da depressão. Trad. de Myriam Campello. São Paulo: Companhia das Letras, 2014. 